\title{
Geothermal reservoirs: From vapour dominated to conductive systems
}

\author{
M.R. Duque \\ Department of Physics of the University of Évora \\ Rua Romão Ramalho, 59,7000-671 Évora, Portugal \\ Phone: 351266745372 ;Fax:351 266745394 ; E-mail: mrad@uevora
}

\begin{abstract}
Geothermal reservoirs are part of the system needed to produce electricity using geothermal fluids. The temperatures in the reservoirs are important for choosing the type of plant. It is also important to know the principal type and amount of fluid that the reservoir can provide. Temperature and pressure in the reservoir will determine whether the fluid is liquid or vapour and whether the system is predominantly conductive or convective. In this work we describe the different types of systems, from the vapour systems where the observed temperatures are highest, up to systems used with geothermal heat pumps that exploit differences in temperature between the soil and the atmosphere. In the last part of the work we present a low-enthalpy geothermal reservoir, located near an old building of the Évora University at Alentejo, in the South of Portugal, that is used to climatize the rooms located in the cloisters of the building. We present the device and some problems related to the exploitation of this reservoir.
\end{abstract}

\section{Key words}

Geothermal reservoir, geothermal energy, geothermal exploration, plant types, geothermal heat pumps.

\section{Introduction}

With the rise of fossil fuel prices and the increased pollution they produce, There has been an increase in research and investment in renewable energy. We see that with increased energy demand, man has been forced to use energy sources that in the past were unexplored. This has led to the development of new methods of research and exploration and improvements through new techniques.

In this work we speak about geothermal energy, a renewable energy whose utilization has grown in recent years due to investment and research in new technologies and due to the necessity of reducing atmospheric pollutants. Geothermal resources are also much larger compared to all fossil fuel resources put together.

\section{Some historical notes}

Geothermal resources have been used for centuries for balneological purposes. The first deep drilling made to investigate the deeper resource commenced at Larderello
(Italy) in 1856, and the first power generation began in 1904 [1]. The first real power development at Larderello commenced in 1913, when a $12.5 \mathrm{MW}$ electric plant was in continuous operation there. The resource used was a steam-dominated resource. The spread of technology to other parts of the world was slow during the first part of the twentieth century[2]. Electricity was first generated at Wairakei (New Zealand) in 1958, from a hightemperature liquid geothermal resource. In the United States of America, the electricity production from geothermal resources only commenced in 1960, at The Geysers in California. Since that time, the development of steam and liquid-dominated resources for power production has begun in many countries worldwide, with a total installed capacity of 11180.2 MW using 551 units[3](data from 2012).

With the use of geothermal heat pumps, direct applications of geothermal fluids are found all parts of the world. The use of geothermal heat pumps grew so rapidly that it is difficult to present accurate data related to the number of installations. Another point is that an elevated number of geothermal plants is installed by private entities, and there are countries such Portugal where these installations are not registered. IGA data base [3] reports an installed capacity of $32679.3 \mathrm{MWt}$ and an annual use of $196185.1 \mathrm{TJ} /$ Year. This represents $67 \%$ of the direct utilization of geothermal fluids.

\section{Types of plants and reservoirs}

In order to have a plant producing electricity at a given location, it is necessary to have at depth a reservoir with hot water or steam, a heat source which heats the water or steam, and a means of carrying water or steam to the surface where the plant is located.

Geothermal reservoirs can be found in nature in regions with aquifers filling pores or faults and cracks, or can be produced by man, in regions formed by dry rocks having high temperatures (HDR). In these cases, water must be sent from the surface to the reservoir and, once heated by the rock, return again to the surface to be used. This method is sometimes used in conventional reservoirs when the water supply is less than the amount of water or steam withdrawn from the reservoir. 
There are two main types of high-temperature geothermal reservoirs: vapour dominated and liquid dominated (both liquid and vapour ). A natural vapour dominated reservoir

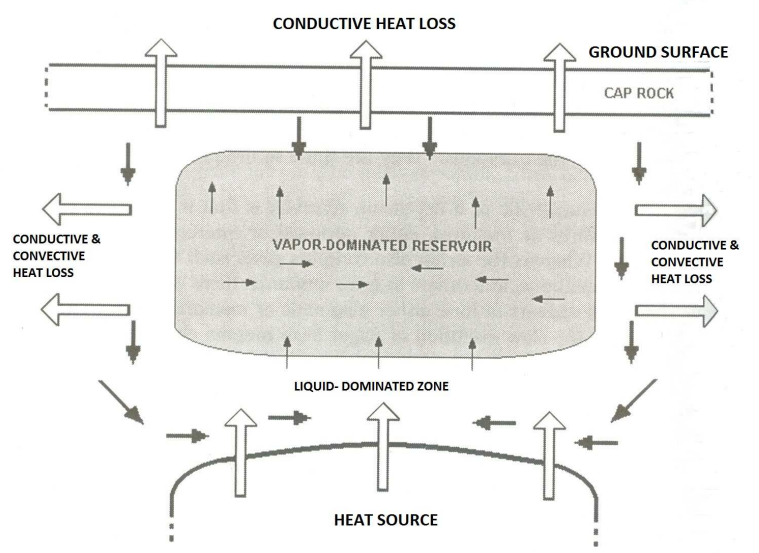

Fig.1. A model for creation and operation of a steam reservoir (adapted from[1]).

contains steam with pressure close to steam-static, and temperatures near saturation. As an example of this type of reservoir, we can mention The Geysers, in the USA, which is the world's largest field by production (18 geothermal plants producing $7061.6 \mathrm{GWh} /$ Year. This corresponds to $42.5 \%$ of the geothermal energy produced in the USA).Another example of this type of reservoir is Larderello. Reservoir conditions in The Geysers were initially those of saturated steam. Volumetric analysis has shown that much more steam has been produced from this field than could be stored as immobile liquid. In a steam dominated reservoir the fluid distribution is controlled by the flow of steam moving up and the water moving down. If the mass fluxes of water moving down and steam moving up are roughly similar, and the vertical pressure gradient is near steam-static, the relative permeability to water must be low. The flowing steam occupies most of the fracture space, and water occupies the remaining pore space. The mass of water in the reservoir is much greater than the mass of steam. Due to the decrease of steam production it is necessary to inject water through wells into the reservoir. In The Geyser the mass of the injected fluid (in 1969) was equivalent to $25-30 \%$ of the extracted steam. In 1995 another project was initiated to inject treated wastewater from the city of Santa Rosa. A pipeline was constructed that was capable of providing 29.5 million liters of water. This injected water stabilizes the steam production. Water injection also has the benefit of reducing $\mathrm{H}_{2} \mathrm{~S}$ in the fluid.

In high temperature geothermal reservoirs, a decline in pressure caused by exploitation may initiate boiling in part or all of the reservoir. The changes caused by exploitation will include changes in the steam/water ratio, as well as pressure and temperature changes. The reservoir can be considered uniformly mixed, containing steam and water, or a vapor-dominated zone overlying a liquid-dominated zone. The first approach ignores gravity; the second assumes gravity is dominant. Both assume steam and water in thermal equilibrium.

Vapor-dominated geothermal fields are located in regions of recent volcanism, near the borders of tectonic plates. In order to form a heat reservoir, the anomalous magmatic intrusion should encounter porous and permeable waterfilled rock strata. Within the reservoir, convection currents of hot water and/or steam are set up and the temperature difference between the top and bottom of the reservoir is not significant. In order to prevent the escape of hot reservoir fluids through convection, there is an impermeable cap rock or a cap rock with low permeability, overlying the reservoir.

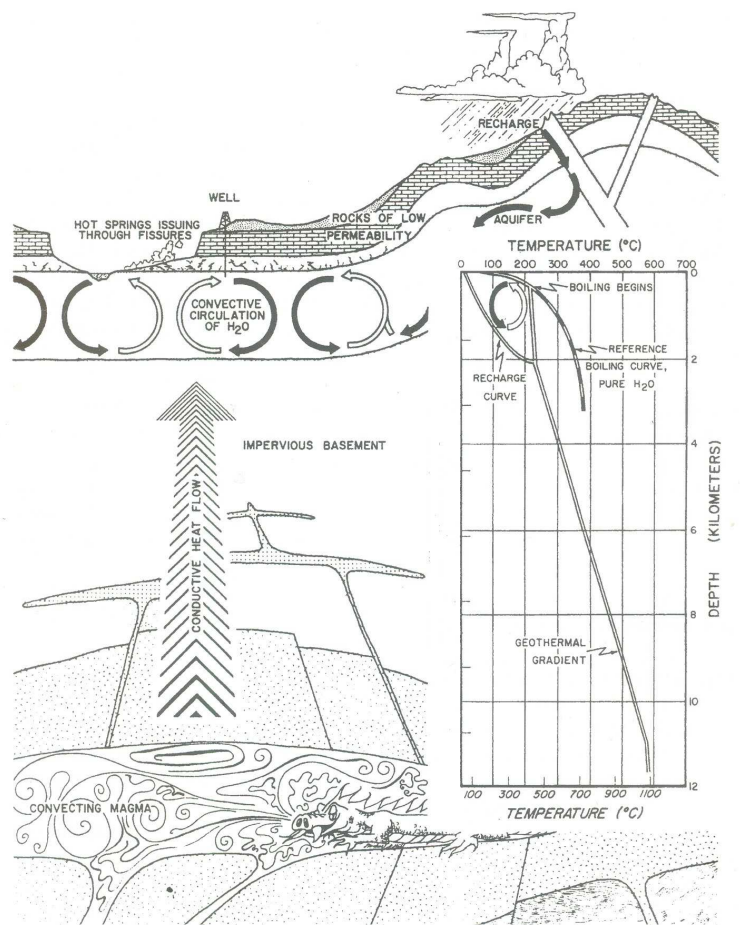

Fig.2. Conceptual model of a hot water geothermal system (adapted from[2]).

Dry-steam power plants were the first type of geothermal power plant to achieve commercial status[4]. Since the geofluid consisted solely of steam, it was easy to hook up a mechanical device to take advantage of the available energy. Dry-steam plants tend to b e simpler and less expensive than the flash-steam plants, because there is no geothermal brine to contend with. There was 63 units of this type, in operation in 2012 [3] (see Table I).

When the geothermal wells produce a mixture of steam and liquid, the single-flash plant is a relatively simple way to convert the geothermal energy into electricity. A typical $30 \mathrm{Mw}$ single-flash power plant needs 5-6 production wells and 2-3 injection wells.

Table I. - Units ,Installed Capacity and Produced Energy

\begin{tabular}{|l|c|c|c|}
\hline \multicolumn{1}{|c|}{ TYPE } & UNITS & $\begin{array}{c}\text { INSTALLED } \\
\text { CAPACITY(MW) }\end{array}$ & $\begin{array}{c}\text { ENERGY } \\
(\text { GWh/Year })\end{array}$ \\
\hline Dry Steam & 63 & 2862.0 & 15750.6 \\
\hline Single Flash & 150 & 4715.1 & 28358.0 \\
\hline Double Flash & 64 & 2182.7 & 14426.2 \\
\hline Binary & 246 & 1267.3 & 6308.1 \\
\hline Back Pressure & 26 & 146.6 & 2393.4 \\
\hline Hybrid & 2 & 6.5 & 10.0 \\
\hline
\end{tabular}

The double-flash plant is an improvement of the singleflash design. It can produce $15-25 \%$ more power output for the same geothermal fluid conditions. The plant is 
more complex, more costly and requires more maintenance but the extra power output justifies the use of such plants. In Table I we can see the different types of plants the number of units in operation, the installed capacity and the produced energy. We can see that the single-flash units (150) produce $42 \%$ of the geothermal energy.

In some geothermal reservoirs, water temperature is not enough to produce steam so binary plants are used. This type of units work with low enthalpy reservoirs. They are used in Hot Dry Rock reservoirs and in small power plants. We can see in Table I (data obtained in the IGA data base) that there was, in 2012, 246 units in operation but the energy obtained was only $6308.1 \mathrm{GWh} /$ Year (only $9,4 \%$ of the total energy produced).

A Type of geothermal environment whose hot water is almost completely sealed from exchange with surrounding rocks is called a geopressured system. Such systems are found in basins in which very rapid filling with sediments takes place, resulting in higher than normal pressure of the hydrothermal water. The first identified field of this type was in the Gulf of Mexico, at a depth between 6 and $8 \mathrm{Km}$, with pore pressures of up to $130 \mathrm{MPa}$ and temperatures in the range $150-180^{\circ} \mathrm{C}$. Reservoirs of this type are not yet explored.

One source of water at temperatures above the mean surface is from aquifers that are so deep that their temperature is raised by the normal geothermal gradient. The mechanism of heating the water is by conduction. The fluid flow in the aquifer must be slow enough for the water to be heated by conductive heat flow. When thermal conductivity of the rock is low, such as in sedimentary regions, the geothermal gradient increases and hot water can be found in regions with normal heat flow. In these cases water can be used in applications like district heating.

Many warm springs can be found along major fault systems and fractures. Such channels provide the means for circulation of meteoric water to depths where it is heated to local temperatures and then returned to the surface. These are a form of convective system. The driving force for the circulation is the density difference between the cool descending water and the hotter rising water.

The production of electricity by geothermal fluids can be present in any type of reservoir. Binary plants, which operate with lower temperatures, are the most widely used. Hot Dry Rock reservoirs are operated, or are being prepared to operate, using binary plants, while older reservoirs, located in specific regions, continue to be explored. The development of geothermal heat pumps and the possibility of their being assembled anywhere means that geothermal energy can be seen as a viable method for heating and cooling of buildings. Direct uses of geothermal fluids have also increased in recent years.

\section{The deviced used at Evora University}

The geothermal reservoir we are studying is located in a nearby old building of the Évora University, dating from the $16^{\text {th }}$ century. The water retrieved from the reservoir circulates at $70 \mathrm{~cm}$ depth, from the boreholes traversing the top of the reservoir, to a heat pump where the water is heated in winter and cooled in summer. After circulating in the building, the water returns to the holes. The device is operational but the efficiency obtained is low. Work is done to minimize energy losses before waters enters into the heat pump and when waters returns to the holes.

\section{A. The reservoir}

In order to delineate the lateral borders of the aquifer, four holes were drilled approximately 100 meters from each other. The maximum depth of the holes was initially 100 meters, but now is less.

The main geologic unit traversed by the holes is granitoid gneiss and sometimes migmatite, amphibolites and haplite.

Flow tests performed in the holes show flow rates between 6001/hour (hole RA4) and 90001/hour (hole RA2). The studies of flow and those obtained using the device, show hydraulic interaction between holes RA1 and RA2. The amount of water that passes from RA1 to RA2 is about $66001 /$ hour and the amount that passes from RA2 to RA1 is about 55001/hour. This fact may be related with the different values of hydraulic transmissivity obtained in holes RA1 and RA2.

The hydraulic transmissivity values obtained varies between $0.30 \mathrm{~m}^{2} /$ day in hole RA4 to $2.64 \mathrm{~m}^{2} /$ day in hole RA1[5]. This low values of transmissivity indicates that the flow is made mainly through fissures. The temperature of the water found in the holes is $18^{\circ} \mathrm{C}$.

\section{B. Soil and air temperatures found in Évora}

Mean air temperature values obtained in Évora in January vary between $5.8^{\circ} \mathrm{C}$ and $12.8^{\circ} \mathrm{C}$. In July and August we have mean air temperature values between $16.3^{\circ} \mathrm{C}$ and $30.2^{\circ} \mathrm{C}$. Sometimes we have temperatures of 1 or $2^{\circ} \mathrm{C}$ in winter and $40^{\circ} \mathrm{C}$ in summer.

The pipes through which water circulates are at $70 \mathrm{~cm}$ depth. Temperature values obtained in soil, covered with grass, in 2012, near the city of Évora, show values of $13^{\circ} \mathrm{C}$ at $70 \mathrm{~cm}$ depth in January and $24^{\circ} \mathrm{C}$ in August. Temperature variations at $70 \mathrm{~cm}$ depth are of the order of $0.2^{\circ} \mathrm{C}$. Although the penetration depth depends on the thermal conductivity of the material being studied, and the thermal conductivity of the gneiss is higher than

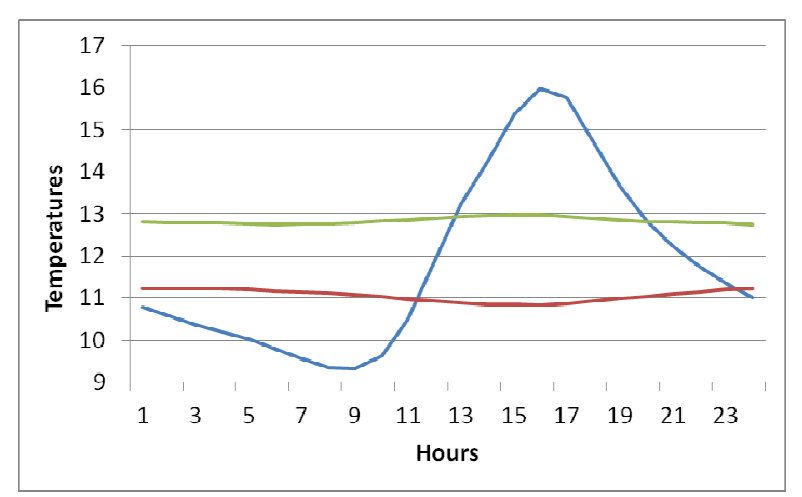

the

Fig.3. Temperatures obtained in the soil at depths of $0 \mathrm{~m}$ (blue), $0.30 \mathrm{~m}$ (red) and $0,70 \mathrm{~m}$ (blue)

thermal conductivity of the soil, we can use, as a first approach the temperatures measured. Another factor that 
makes temperatures less elevated is that the soil surface is covered with grass that sometimes is watered. The soil in the area of the holes is stripped of vegetation. Figure 3 shows temperatures obtained at different depths during one day in January. We can see that temperatures of the soil at $0,70 \mathrm{~m}$ depth are near $13^{\circ} \mathrm{C}$.

\section{Water temperature in the pipes}

The study of the temperature in depth shows that the pipes through which water circulates, is subjected to temperatures which differ 5 to $6{ }^{\circ} \mathrm{C}$ from the water temperature. The influence of these temperatures on the temperature of the water, will depend on the velocity of the water in the pipes, the diameter of the pipes and the thermal conductivity of the constituent material of the pipes.

Assuming that the heat transfer between water, pipes and soil is made mainly by conduction and using values of $0.6 \mathrm{WK}^{-1} \mathrm{~m}^{-1}, 3.0 \mathrm{WK}^{-1} \mathrm{~m}^{-1}$ and $0.23 \mathrm{WK}^{-1} \mathrm{~m}^{-1}$ [6], for the thermal conductivity of water, gneiss and pipes respectively, we obtain, for temperature values of the water near the inner wall of the pipe, $11.8^{\circ} \mathrm{C}$ in winter and $20.2^{\circ} \mathrm{C}$ in summer.

\section{Conclusions}

The electricity generation from geothermal resources is currently performed in all types of reservoirs except those associated with resources under high pressure, found at great depths, in sedimentary basins. In our days, plants of all types are in operation. Binary plants are widely used because they can work with low-enthalpy resources and are used in Hot Dry Hot reservoirs. The use of these types of reservoirs has grown in recent years due to discoveries of new reservoirs located outside the borders of the tectonic plates.
Direct use of geothermal fluids has increased in recent years highlighting the use of geothermal heat pumps, which are used for air conditioning of buildings at relatively low prices, that are currently responsible for $67 \%$ of the direct utilizations of these fluids.

The device used at the University of Évora for cooling and warming old rooms presents a low efficiency, due to two facts: the low flow rate found in the holes and the influence of soil temperature in the temperature of the water in the pipes. The depth to which the pipes are placed allows water does not suffer the influence of daily temperature variations but the water is subjected to seasonal temperature variations.

\section{Acknowledgement}

The soil temperature data we used are owned by CGE (Geophysical Center of the University of Évora). Our thanks for permission to use them.

\section{References}

[1] M. A. Grant, P.F. Bixley. Geothermal Reservoir Engineering, Elsevier, Amsterdam (2011),pp 9-27.

[2] H. Gupta, S. Roy, Geothermal Energy. An Alternative Resource for the $21^{\mathrm{ST}}$ Century, Elsevier, Amsterdam (2007),pp 11-13 and 49-59.

[3]http://www.geothermal_energy.org/226,installed_generating capacity.html. -retrieved 14.11.2012.

[4] R. DiPippo, Geothermal Power Plants. Principles, Applications, case Studies and Environmental Impact, Elsevier, Amsterdam (2008), pp 79-184.

[5] V. L. Montes, captação de Águas Subterrâneas para Aproveitamento Geotérmico-Caso de Estudo do Colégio do Espírito Santo, Universidade de Évora, Évora, Internal Report (2009),pp1-73.

[6] C. Jaupart, J.-C. Mareschal, Heat Generation and Transport in the Earth, Cambridge University Press, London (2011),pp 416. 